\title{
Facebook: um possível espaço digital de aprendizagem cooperativa da Matemática
}

\author{
Aline Silva De Bona - vivaexatas@yahoo.com.br \\ Léa da Cruz Fagundes - leafagun@ufrgs.br \\ Marcus Vinicius de Azevedo Basso - mbasso@ufrgs.br
}

Resumo: O artigo apresenta um recorte de uma pesquisa-ação de doutoramento em Informática na Educação Matemática, que define espaço de aprendizagem digital da matemática, como exemplo a rede social Facebook, e aponta a aprendizagem cooperativa como uma forma de aprender a aprender matemática atrativa aos estudantes mediada pelas tecnologias digitais online. Tendo como referencial a Teoria do Jean Piaget para explicar a aprendizagem cooperativa e a forma de abstração reflexionante registrado no espaço digital. Um dos resultados desta pesquisa é a construção dos conceitos de matemática de forma cooperativa no Facebook por 24 estudantes do $2^{\circ}$ ano do ensino médio integrado do IFRS - Campus Osório em 2012-1.

Palavras-chaves: Abstração Reflexionante, Problemas de Matemática, Rede Social.

\section{Facebook: a possible space of digital cooperative learning of Mathematics}

\begin{abstract}
The article presents an outline of an action research doctorate in Computer Science in Mathematics Education, which defines the space of digital learning of mathematics, such as the social network Facebook, and points to the cooperative learning as a way of learning to learn math attractive to students mediated by digital technologies online. Taking as reference the Theory of Jean Piaget to explain the cooperative learning and reflective abstraction form recorded in the digital space. One result of this research is the construction of math concepts cooperatively on Facebook for 24 students in 2nd year high school integrated IFRS - Campus Osório in 2012-1.
\end{abstract}

Keywords: reflective abstraction, Math Problems, Social Network.

\section{Introdução}

As tecnologias digitais online estão a cada dia mais presentes na vida dos estudantes, e o uso que estes jovens, particularmente com idade entre 13 anos e 17 anos, fazem é diversificado, tanto para informação como para comunicação, pois desde uma simples consulta de endereço no GoogleMaps até uma avançada pesquisa sobre fractais em artigos acadêmicos, e ainda a forma de comunicação adotada com as pessoas em geral, familiares, amigos e professores é "imediata".

A palavra "imediata", ou sinônimos, é citada por 23 estudantes dentre 24, com 14 e 15 anos, quando questionados sobre porque gostam de se comunicar via tecnologias digitais online, em respostas do tipo: "aviso minha mãe na hora que vou me atrasar pelo ipad, e tudo fica ok já que é imediato", "termino de entender alguma coisa legal de matemática e já posto no facebook para todos terem a informação de imediato com minhas palavras..."; "geralmente é conversando online que pego as informações e entendo as coisas ... é imediato que a informação na conversa é mais lógica e rápida, 
daí online faço 2 coisas em um, aprendo e falo, trocando mais rápido, sem enjoar do papo".

Desta forma, o recurso tecnologia digital online é atrativo aos estudantes, sendo mobilizador do processo de aprender a aprender matemática, segundo Bona (2010), tanto para contextualizar de forma interdisciplinar os conceitos de matemática, como proporciona um espaço de aprendizagem cooperativa entre os estudantes, para Bona, Fagundes, Basso (2011). Além disso, Bona et all (2011), apontam que há a necessidade de uma intervenção transformadora dos professores em relação ao uso das tecnologias na sala de aula, baseando-se em um processo de aprendizagem construtivista, de Piaget $(1973,1975,1977)$. Ou seja, as tecnologias digitais online potencializam o processo de aprendizagem dos conceitos de matemática quando ancorados em práticas docentes inovadores e que visem à interação do estudante com seu próprio processo de aprendizagem.

O artigo é um recorte da pesquisa-ação (Barbier, 2004) de doutoramento, na área da Informática na Educação Matemática, de um dos autores e de seus orientadores, que tem como questão: Como analisar e compreender o processo de aprendizagem cooperativa dos conceitos de matemática no espaço de aprendizagem digital?

Assim, o objetivo deste artigo é demonstrar a construção dos conceitos de matemática, por meio da resolução de problemas, no espaço de aprendizagem digital via aprendizagem cooperativa, durante 2012-1, no IFRS - Campus Osório, pelos 24 estudantes do $2^{\circ}$ ano do ensino médio integrado em informática, baseados em uma prática docente dialogada entre professor e estudantes. $\mathrm{O}$ espaço de aprendizagem digital da matemática adotado pelos estudantes desta pesquisa-ação é a rede social Facebook, onde fazem uso da estrutura de Listas Fechadas neste ambiente virtual e de aplicativos como Docs.

O tema desta pesquisa-ação é relevante para a área da Informática na Educação Matemática, segundo Fiorentini e Lorenzato (2007), pois já se sabe que as tecnologias digitais contribuem para uma educação de qualidade, no entanto ainda carece de pesquisas que demonstrem como fazer, ou melhor, como implementar ações que viabilizem junto com as tecnologias digitais a construção dos conceitos de matemática na Escola Básica. Então, o artigo aponta ações e a análise do processo de aprendizagem cooperativa dos estudantes mediados pelas tecnologias digitais online na resolução de problemas de matemática. $\mathrm{O}$ artigo está organizado na introdução, onde consta o tema, objetivo, questão de pesquisa e metodologia, depois a discussão teórica e prática da ação de pesquisa. Por fim, os resultados e considerações finais e referências bibliográficas.

\section{Facebook: um espaço digital de aprendizagem cooperativa da matemática}

Cada vez mais o tempo que os estudantes têm de aula presencial em cada disciplina é menor, e os objetivos e conteúdos a serem cumpridos em determinado período de tempo, são enormes. No entanto, de acordo com os Parâmetros Curriculares Nacionais (Brasil, 1999), tem-se para a Educação Matemática uma liberdade de trabalho dos professores muito grande de como proporcionar atividades que viabilizem a construção dos conceitos de matemática adaptado a cada contexto de estudantes e instituição de ensino. Desta forma, se faz necessário explorar novos espaços de aprendizagem além dos muros da escola, e ainda descobrir recursos que mobilizem o aprender a aprender dos estudantes nestes diversos espaços de aprendizagem, recursos 
estes apontados pelos estudantes como as tecnologias digitais online (Bona, 2010).

Assim, Bona, Fagundes e Basso (2011), definem o que é um espaço de aprendizagem digital como um local não situado geograficamente onde o processo de ensino-aprendizagem ocorre através da organização e aplicação de uma concepção pedagógica, baseada na comunicação, interação, trabalho colaborativo do professor com os estudantes, e cooperativo dos estudantes entre si e com o professor.

Este local é escolhido pelos estudantes em conjunto com a professora de matemática, um dos autores, em 2012-1, como a rede social Facebook, devido a possibilidade de atender as características necessárias para compor este espaço que são: ausência de limites via internet, ausência de disposição espacial em muitos momentos, opacidade (criação de conceitos espaciais - simulação -, associados ao espaço real, e a possibilidade de relações entre objetos neste espaço), virtualidade (que é a representação digital de algo que é real), e a telepresença (presença não física do professor, estudantes e demais agentes). Tais características citadas também são destacadas por Peters (2009).

Ainda, o Facebook dispõe de algumas vantagens frente a outros ambientes virtuais no que tange a possibilidade deste ser um espaço de aprendizagem digital que vise proporcionar o aprender a aprender de matemática, como: possibilidade de se criar grupos fechados na forma de Listas onde todos os integrantes são convidados a participar e tem as mesmas atribuições; a programação de que cada postagem pode ser comentada por todos os participantes e que cada vez que ela é comentada por alguma pessoa ela torna-se a primeira postagem na lista; existem aplicativos como o Docs que permite anexar documentos em formatos diversos como ppt, pdf, e outros, além da opção de linkar vídeos, músicas, sites e outras multimídias; as postagens podem ser construídas como hipertextos e estas podem ser repostadas coletivamente; os chats do grupo podem ser feitos coletivamente e são salvos como mensagens do grupo visíveis a todos sempre; tudo o que é realizado no Facebook está salvo por tempo indeterminado, o ambiente é free e de acesso de todos, pode ser acessado por todo navegador de rede.

Cabe destacar que o Facebook não gera custos para a instituição de ensino e nem para os estudantes de forma individual, já que basta ter acesso a internet, e uma conta de email. A rede social é diferente de espaço de aprendizagem digital, assim como difere de uma comunidade virtual, porque os laços entre os participantes de uma comunidade são livres e apenas um objetivo os une, por exemplo, e na rede social basta ser conhecido de pessoas ou ter curiosidade sobre uma informação, enquanto que para ser espaço digital de aprendizagem requer um objetivo claro entre todos os participantes, e um comprometimento com este objetivo que é a aprendizagem de matemática. Desta forma, se faz necessário no inicio das atividades a criação de um contrato didático entre estudantes, professora e pais/responsáveis, sobre os direitos e deveres de cada participante do espaço tanto presencial como digital.

Este contrato conta de cláusulas como: "Todos tem de ler e tentar contribuir com os problemas propostos de matemática online, mesmo com dúvidas apenas"; "Todos temos de responder as perguntas feitas em 48horas, e explicar o que acharmos de errado nas contas dos outros"; "A professora deve perguntar sempre os desenvolvimentos que não entender antes de dizer que não tá certo"; "Os alunos devem se comprometer na sala de aula online e presencial a prestar atenção em tudo antes de perguntar o que já foi desenvolvido pela professora ou colegas"; "No espaço digital só pode coisas com relação a matemática, mesmo que de outras matérias, só se tiver conteúdo de matemática, até as piadas online só com matemática"; "Os pais não podem 
ser do grupo mas podem ajudar os filhos juntos e o filho avisa que o pai tá ajudando para ser justo"; "Todos devem respeitar as dificuldades de cada um e tb de internet ruim quando tem muito vento e a $3 G$ pifa".

O funcionamento deste espaço digital no Facebook é baseado na resolução de problemas de matemática, onde os estudantes e a professora podem postar e também comentar as resoluções são feitas via comentários, e os anexos são por imagem, aplicativo Docs. Durante este trabalho, que vem sendo pesquisado desde 2011, com enorme apoio dos pais e alegria dos estudantes, identificou-se que a aprendizagem cooperativa entre os estudantes durante a resolução dos problemas estava sendo potencializada, ou seja, os estudantes estavam resolvendo todos os problemas entre si, não dividindo atividades, mas cooperando entre si, inclusive na correção de erros e apontamentos de dificuldades.

Para Piaget (1973), cooperar na ação é operar em comum, por meio de novas operações do tipo correspondência, reciprocidade e/ou complementaridade as operações feitas por cada colega, enquanto que colaborar é apenas a reunião de ações que são feitas isoladamente por cada colega. E cada vez que um estudante coopera com outro, ou com outros, ocorrerem abstrações, sejam empíricas ou reflexionantes, porque o estudante tem de abstrair da ação do colega. Segundo Piaget (1977, p.5-6), abstração empírica "se apoia sobre os objetos físicos ou os aspectos materiais da própria ação", como movimentos, enquanto que a abstração reflexionante refere-se "sobre as formas e todas as atividades cognitivas do sujeito, para delas retirar certos caracteres e utilizá-los para outras finalidades, como novas adaptações". Assim, a abstração reflexionante comporta dois aspectos essenciais: o reflexionamento, que é a projeção daquilo que foi retirado de um patamar inferior sobre um patamar superior, e a reflexão, que pode ser compreendida como o ato mental de reconstrução e reorganização sobre o patamar superior do que foi transferido a partir do inferior.

$\mathrm{Na}$ resolução dos problemas feita pelos estudantes no Facebook é possível analisar e compreender o processo de aprendizagem cooperativa dos conceitos de matemática, sendo tal processo analisado à luz da Epistemologia Genética de Piaget (1973), da Abstração Reflexionante (1977), e dos Estudos Sociológicos (1973).

Desde fevereiro até julho de 2012, analisaram-se as resoluções de conteúdos de trigonometria no triângulo retângulo e no círculo trigonométrico, geometria plana e geometria espacial (exceto pirâmides), com 24 estudantes do $2^{\circ}$ ano do ensino médio desta pesquisa, apontando-se algumas quantificações interessantes: são necessários 8 estudantes para resolver um problema de nível médio de trigonometria, com uma média de 3 postagens cada um, até a sua resolução completa e de compreensão de todos. Já para geometria plana são 11 estudantes e as postagens variam de 3 até 5 cada um, enquanto que para geometria espacial são 14 estudantes e geralmente 4 postagens de cada um.

Além disso, é usual que os estudantes não online durante a resolução de um problema tenha dois tipos de ações: curtir a postagem do problema e alguns passos da resolução sendo possível compreender como este estudante entendeu o desenvolvimento da questão; e/ou posta um comentário elogiando ou fazendo questões com dificuldades ou com outra forma de resolver o problema.

Então cada problema envolve, em média, de trigonometria 16 estudantes, de geometria plana e espacial 23, o que demonstra um envolvimento máximo dos estudantes com a resolução dos problemas em horários variados e com uma média de acesso por dia de 3horas. Paralelamente aponta-se que nas avaliações de trigonometria a 
média da turma foi 7,8 de 10, e apenas um estudante obteve 6,7; em geometria plana foi de 8,2, e dois estudantes obtiveram 5,4 e 6,8, não sendo o mesmo de antes; e geometria espacial, foi de 8,7, com apenas um estudante 6,8, também não sendo nenhum dos anteriores. Estas quantificações demonstram a compreensão dos estudantes quanto aos conceitos de matemática, e demonstram que o Facebook é um espaço de aprender a aprender matemática cooperativamente.

\section{Problema de Trigonometria resolvido no Facebook de forma cooperativa}

Nesta seção elucida-se um problema de trigonometria no triângulo retângulo resolvido pelos estudantes no Facebook de forma cooperativa com a finalidade de exemplificar os conceitos de abstração empírica e reflexionante, e as formas de cooperação, além da funcionalidade do espaço construída pelos estudantes para aprender a aprender matemática. As discussões em torno das soluções apresentadas pelos estudantes no Facebook são longas, razão pela qual aqui serão apresentados trechos transcritos, suficientes para a compreensão das resoluções propostas.

\section{ㅍ. I 201 - Grupo de Estudos}
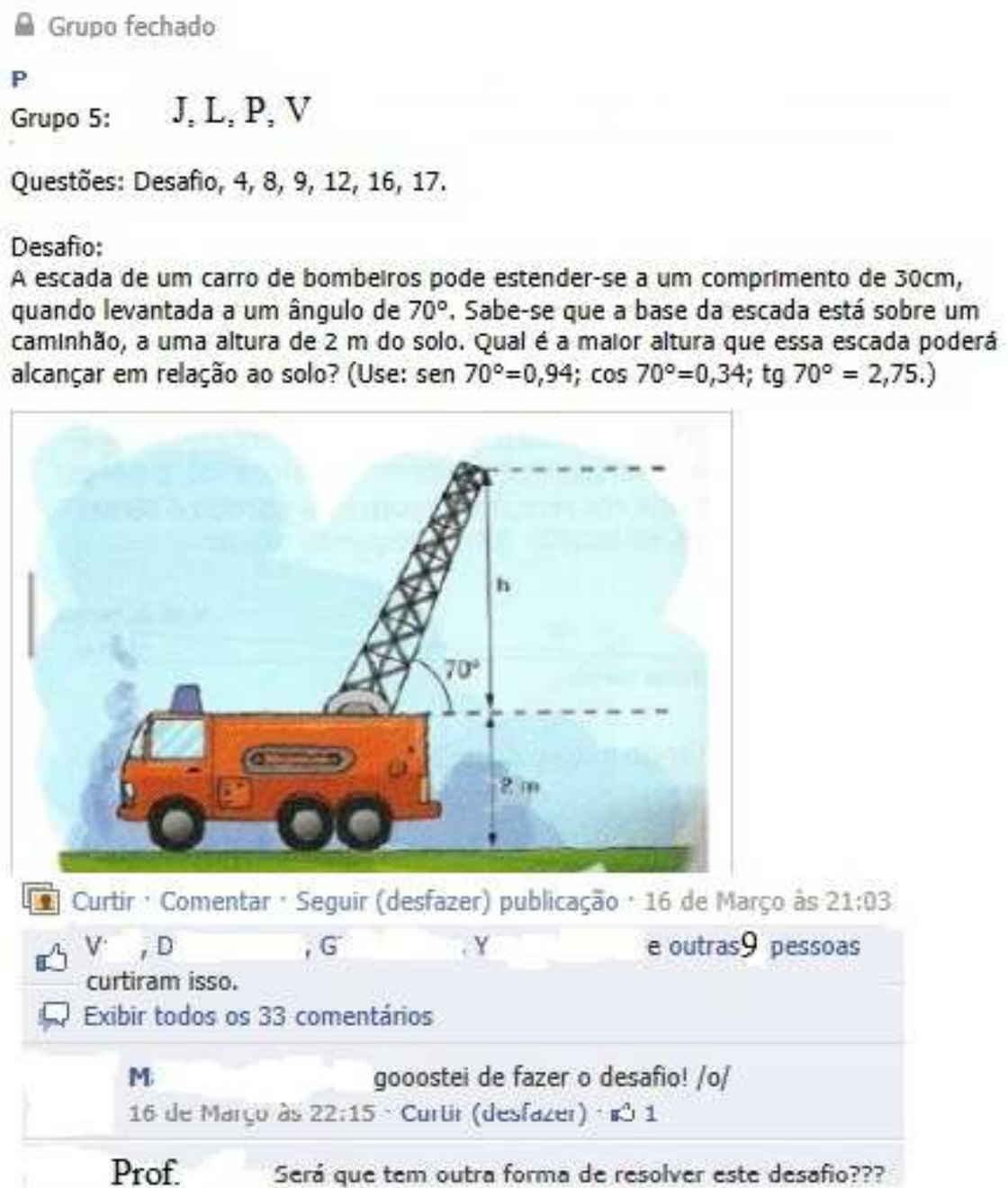

Figure 1. Layout do Facebook com problema de trigonometria de março/2012 
Na figura 1 as imagens dos estudantes foram retiradas, mesmo se tendo o termo de consentimento de todos os estudantes assinado por pais e responsáveis, mas opta-se por este sigilo, adotando-se as letras iniciais dos seus nomes e quando existe algum nome repetido, acrescenta-se a letra do segundo nome. Nesta figura observa-se: a organização dos estudantes em grupos de até quatro pessoas para dividir os problemas/questões/desafios a serem resolvidos pela turma no Facebook, como assim escolheram; além dos 4 colegas de grupo 4 colegas curtiram com comentários (que são as pessoas que aparecem as inicias dos nome no curtir abaixo da imagem da questão), mais 9 que apenas curtiram, e um colega que comentou sem curtir, além da professora que comentou a resolução também; e consta a informação de "Exibir todos os 33 comentários", sendo estes a resolução do exercício entre os 4 componentes do grupo mais 7 colegas que participaram, cada um com 2 ou 3 comentários, e um comentário de 4 dos colegas que curtiram.

A resolução do problema está correta e a imagem que representa o triângulo retângulo foi construída pelo grupo no Paint com montagens de imagens pesquisadas na internet. A seguir alguns comentários da resolução que apontam as conceituações de aprendizagem cooperativa:

J: " Fiz a imagem como interpretei o problema, q tal?!"

P: "Bah, é isso J, tb fiz o mesmo, imaginei q a escada é a hipotenusa do triângulo retângulo, mas não sabia o q fazer c/a altura do caminhão, ficou tri..."

As interações de $\mathrm{J}$ e $\mathrm{P}$ demonstra a abstração empírica verificada pelo estudante $\mathrm{P}$ sobre a imagem feita pelo seu colega $\mathrm{J}$, num primeiro momento.

$\mathrm{V}$ : "Partindo deste triângulo devemos usar q hipotenusa é 30m, e dai queremos saber o cateto oposto (CO) do ângulo de $30^{\circ}$, ne?"

A interação de $\mathrm{V}$ com relação a imagem de $\mathrm{J}$ já é uma abstração reflexionante, pois este extraí informações em conformidade e agrega outras para a resolução, fazendo paralelamente uma operação em comum por correspondência e complementaridade, ou seja, a ação é cooperativa, primeiramente em concordar com o colega e depois por completar com qual conceito de razão trigonométrica usar.

$\mathrm{J}$ : "hum...pensei em usar tangente e depois teor de pitágoras, q tal?"

L: "Não entendo, J, pq tangente, se temos a hipotenusa, o ângulo e quero CO?"

Analisando a ação de $\mathrm{J}$ com relação a $\mathrm{V}$ consta-se uma outra forma de pensar cooperativamente, mas não por reciprocidade, como já se verifica com L, que concorda com $\mathrm{V}$, e tenta ajudar o colega $\mathrm{J}$ que deseja usar um outro caminho de resolução.

T: "É, L, só usar sen $70^{\circ}$, q enunciado dá, e fica: $0,94=(h+2) / 30 \ldots . . . "$

M: "Epa, 2 da onde?"

Já na sequencia dada por $\mathrm{T}$ em relação a $\mathrm{V}$ verifica-se um equívoco de conceito de matemática rapidamente chamo a atenção pelo colega $\mathrm{M}$, e explicado em seguida por U. Tais reflexionamentos fazem parte do processo de aprendizagem destes estudantes em construir a abstração reflexionante necessária até a resolução do problema. Ainda o estudante $\mathrm{C}$ reitera a explicação de $\mathrm{U}$ demonstrando uma ação de cooperação por reciprocidade, pois além de concordar com o colega, tanto em interpretação e em conceitos de matemática, também em método de resolução.

T: "Da altura do caminhão q tb conta p/tamanho ne?"

U: "Tá louco, mas as razões trigonométricas são no triângulo e o tamanho do caminhão tá fora....nada de 2..."

C: "A sora sempre diz p/ter foco no conceito de matemática e vejam bem se já tiramos dados do problema, interpretamos e sabemos o q quer é só calcular o seno sem 
aquele 2 , e resolvido...ves tão misturando td"

A: "Eu penso como L e C, fiz: $h=0,94 \times 30=28,2 m$ e dai somei 2 do caminhão, q ficou $30,2 m^{\prime \prime}$

A participação do estudante A é de cooperação dos seus 3 tipos e de um processo de abstração reflexionante após vários reflexionamentos construídos pela leitura das ações dos colegas, pois quando comenta com sua contribuição a resolução escolhe a que ações dos colegas está se referindo (que no Facebook o colega é notificado se sua solicitação de atenção), no caso o L e C, e termina de resolver usando uma escrita matemática adaptada ao Facebook que não tem símbolos matemáticos.

$\mathrm{K}$ : "Sabe A, eu tb achei quase isso, mas pensei assim: x é base triângulo e dai com tan $70^{\circ}=2,75=h / x$, e $\cos 70^{\circ}=x / 30=0,34 q$ dá $x=10,2, q$ trocando dá $h=$ 2,75 x 10,2 = 28,05 m e com 2 m caminhão, então 30,05m, e agora?"

A interação de K com A e com os colegas em demonstrar outra solução e que dá uma diferença de valor, porém com métodos matematicamente corretos suscita uma discussão de aproximação decimal e de formas de calcular as razões trigonométrica ainda não previstas pela professora talvez, sendo uma demonstração de interesse em pesquisa e aprender a aprender matemática com suas perguntas:"...e agora?". Como descrito antes há muitas interações dos estudantes neste problema e outras formas de resolver inclusive com erros comuns de trocas de identificação de catetos e hipotenusa.

Destaca-se que este problema foi resolvido por todos os estudantes da turma, durante 34 minutos, no dia 16 de março de 2012, as $21 \mathrm{~h} 03$ (ou seja, de noite, fora do horário de aula e numa sexta-feira, isto é, estavam estudando online por interesse próprio, por estarem mobilizados com o espaço digital de aprendizagem) e o último comentário foi de um colega que participou das interações dizendo que gostou de fazer o desafio, onde as letras repetidas do verbo gostar significa alegria em resolver, segundo a fala do próprio estudante.

É evidente a mobilização dos estudantes em resolver os problemas de matemática independente da professora estar ou não online, porque a postagem da professora peguntando sobre outra forma de fazer ocorreu apenas no dia 19 de março às 17h30, já que o horário de atendimento online desta turma via Facebook é nas segundas-feiras das $16 \mathrm{~h}$ até as $18 \mathrm{~h}$.

A interação da professora em sempre fazer perguntas na sua participação é parte da concepção pedagógica adotada neste espaço de aprendizagem digital que é construtivista baseada no diálogo com os estudantes, procurando sempre despertar a curiosidade dos estudantes e também que estes sejam capazes de explicar o que pensar e como resolvem os problemas, para destes reflexionamentos demonstrados nos comentários a professora traçar formas de ação que possibilitem a aprendizagem de cada estudante em relação a aprendizagem dos conceitos de matemática.

Questionou-se os estudantes sobre porque gostavam tanto de resolver os problemas de matemática no Facebook? E o que significa curtir um problema de matemática ou uma interação de colega como comentário na resolução? As respostas assemelham-se muitos em torno da ideia de que: "...estudar no Face é tri divertido, fizemos c/os colegas, e do nosso jeito, e tb as vezes nada para fazer, ali online, estamos pesquisando sobre o q é seno e cosseno e dai já aparece problema e resolvemos juntos...."; "....as vezes na aula to cansado, c/fome por causa bus, muito barulho não dá p/se concentrar direito, mas online dá, é bem fácil, cada um tem seu jeito e forma de pensar, dá p/escrever a todos podem ler ajudar, e dai a gente pode voltar e ver a resolução passo a passo várias vezes e ainda chamar os colegas no chat p/ajudar...."; " 
Curtir significa que a gente gostou ou achou interessante p/o problema, e p/o comentário quer dizer que entendeu e ajudou a pensar, pois ninguém curte aquilo que não entende, ne?"; "Bah quando curto é pq o comentário me ajudo a resolver o problema, ie, ajuda a pensar matemática até fazer a questão, e isso demora e por isso não se curte todos os comentários, pq nem todos se entende, e dai tem de comentar p/perguntar, mas até p/perguntar tem de entender algo, né? dai curtir é entender td."

Atualmente o Facebook desta turma de estudantes tem mais de 100 problemas de cada um destes três conteúdos, além dos projetos de aprendizagem, das correções das avaliações que os estudantes determinaram fazer online como forma de ajudar os colegas e obter diversas resoluções variando as formas de pensar, e os portfólios de matemática entregues por trimestre.

Ainda é importante destacar que alguns problemas os estudantes resolvem até o processo de generalização/demonstração de alguns conceitos de matemática, conquistando assim a abstração refletida, segundo Piaget (1977), que é a abstração do pensamento formal, com a tomada de consciência da própria reflexão. Essa forma de abstração refletida ocorre nestes conteúdos citados geralmente com aproximadamente $55 \%$ dos estudantes, tanto nas resoluções online quando em presenciais.

\section{Resultados e Considerações Finais}

Os resultados desta pesquisa-ação são muitos e eles são cada vez mais surpreendentes quando se analisa os dados, e ainda mais quando se busca questionar os estudantes sobre curiosidades sobre as formas que escrevem matemática e também de como pensam cada uma das suas interações com os colegas.

Alguns resultados já verificados:

1) a definição do espaço de aprendizagem digital da matemática é satisfatória e adequada ao uso que se faz do Facebook, este espaço mobiliza o processo de aprender a aprender de matemática dos estudantes, pois eles se envolvem com os problemas, pesquisam para resolver e se comunicam a qualquer hora com os colegas até entender como se resolver o problema;

2) a aprendizagem cooperativa é potencializada pelo espaço de aprendizagem digital da matemática, particularmente o Facebook;

3) é possível os estudantes aprender a aprender cooperativamente uns com os outros neste espaço digital sem a presença da professora inclusive; é notória a construção dos conceitos de matemática explorados via problemas de matemática no Facebook de forma cooperativa por todos os estudantes e num tempo muito além do previsto pela professora e contemplando conteúdos além do currículo básico escolar;

4) e o professor pode neste espaço digital traçar planejamentos de forma a realmente transformar sua prática docente ou intervenções transformadoras apropriando-se de recursos interessantes aos estudantes para proporcionar momentos de aprendizagem aos estudantes, sejam presenciais ou online, individuais ou coletivos.

O objetivo deste artigo é plenamente cumprido, pois se verifica quantitativa e qualitativamente a construção dos conceitos de matemática, por meio da resolução de problemas, no Facebook via aprendizagem cooperativa, baseados em uma prática docente dialogada, porque como o artigo aponta diferentes momentos de onde a professora-pesquisadora, um dos autores, sempre escuta os estudantes para assim inovar sua prática docente, desde os recursos que são atrativos aos estudantes, até o que estes conceituam/entendem por curtir no Facebook como um espaço digital para aprender 
matemática.

Além disso, é relevante destacar que os 24 estudantes desta turma fazem uso de vídeos explicativos de como resolvem os problemas de matemática em softwares como o Geogebra, hospedam em seu pbworks individual, e linkam para os colegas, e nesta postagem de link ocorre a aprendizagem cooperativa dos demais colegas solicitando explicações e participando com resoluções diferentes demonstrando assim uma apropriação do espaço digital como tecnologia digital online e da forma de aprendizagem que lhes é atrativa que é a cooperativa, em que esta somente é possível de análise pela professora-pesquisadora, pois é mediada pelas tecnologias que permite tudo ficar registrado com propriedade/autoria, ou seja, a ação de cada estudantes está registrada com seu nome.

\section{Referencias Bibliográficas}

BARBIER, R. A Pesquisa-Ação. Série Pesquisa em Educação. Tradução de Lucie Didio. Brasília: Liber Livro Editora, 2004.

BONA, A.S.D. Portfólio de Matemática: um instrumento de análise do processo de aprendizagem. Dissertação (mestrado). UFRGS - Programa de Pós-Graduação em Ensino de Matemática. Porto Alegre: UFRGS, 2010.

BONA, A.S.D.; FAGUNDES, L.C; BASSO, M.V.A. A cooperação e/ou a colaboração no Espaço de Aprendizagem Digital da Matemática. In: RENOTE - Revista Novas Tecnologias na Educação, v. 9, n. 2, 2011.

BONA, et all. Concepções de Currículo, Projetos de Aprendizagem e Interação no Projeto UCA/RS. In: Anais do Sbie - Wie - 22 Simpósio Brasileiro de Informática na Educação e 17 Workshop de Informática na Escola, Aracaju, 2011.

BRASIL. Secretaria de Educação Fundamental. Parâmetros Curriculares Nacionais: Matemática. Brasília: MEC/SEF, 1999.

FIORENTINI, D.; LORENZATO, S. Investigação em educação matemática: percursos teóricos e metodológicos. Coleção Formação de Professores. Campinas: Autores Associados, 2007.

PETERS, O. A educação à distância em transição. São Leopoldo: Unisinos, 2009. PIAGET, J. Estudos Sociológicos. Rio de Janeiro: Forense, 1973. Epistemologia Genética. Porto Alegre: Artmed, 1975.

Abstração Reflexionante: Relações lógico-aritméticas e ordem das relações espaciais. Porto Alegre: Artmed, 1977. 